\title{
USO DE IMAGENS LANDSAT PARA AVALIAÇÃO DA COBERTURA VEGETAL DO PARQUE NACIONAL DE SETE CIDADES (PI), NORDESTE, BRASIL ${ }^{1}$
}

Use of Landsat images to assess the vegetation cover of the Seven Cities National Park (PI), Northeastern Brazil

FRANCÍLIO DE AMORIM DOS SANTOS²

\begin{abstract}
RESUMO: A cobertura vegetal é essencial para proteção dos solos, visto que reduz a energia cinética das gotas da chuva, atenuando o processo de erosão. Portanto, tornou-se relevante avaliar o estado de conservação/degradação da cobertura vegetal do Parque Nacional de Sete Cidades (PARNA), localizado entre Piracuruca e Brasileira, Nordeste do Piauí, através do Índice de Vegetação por Diferença Normalizada (NDVI). O PARNA assenta-se sobre a Formação Cabeças, possui relevo sob a forma de chapadas, predominando linhas suaves. Os Latossolos Amarelos, Podzólico Vermelho-Amarelo e Solos Litólicos do referido PARNA são recobertos por cerrado subcaducifólio, cerrado subcaducifólio/caatinga. O NDVI apontou que, de 1984 para 2013, houve aumento da classe Moderadamente Baixa e supressão da classe Moderadamente Alta. Desse modo, o NDVI aponta um estado de sucessão ecológica, principalmente, após os incêndios ocorridos entre 1990 e 2000. Estudos posteriores devem abordar as características físico-químicas dos solos, atualização da capacidade de saturação e do Plano de Manejo, entre outros, para adequado monitoramento das fragilidades naturais.
\end{abstract}

Palavras-chave: Unidade de Conservação; Cobertura das terras; Sensoriamento Remoto.

\begin{abstract}
The vegetation is essential for soil protection, since it reduces the kinetic energy of raindrops, reducing the erosion process. Therefore, it has become relevant to assess the state of conservation / degradation of the vegetation cover of the Parque National de Sete Cidades (PARNA), located between Piracuruca and Brasileira, Northeastern Piaui, through the Vegetation Index (NDVI). The PARNA sits on Training Heads, has relief in the form of plateaus, predominantly smooth lines. Latosols Yellow, Red-Yellow Podzolic Soil and Litólicos said PARNA are covered by semideciduous cerrado, semideciduous cerrado / caatinga. The NDVI pointed out that from 1984 to 2013, an increase of Moderately Low class and suppression of Moderately High class. Thus, the NDVI shows a state of ecological succession, especially after the fires between 1990 and 2000. Further studies should address the physical and chemical characteristics of soils Update saturation capacity and the Management Plan, among others, to adequate monitoring of natural weaknesses.
\end{abstract}

Keywords: Conservation Unit; Coverage of the land; Remote Sensing.

${ }^{1}$ Pesquisa financiada pelo Programa de Apoio a Pesquisa Científica e Tecnológica (ProAGRUPAR), Edital nº 033 de 14 de abril de 2014, que concedeu bolsas de incentivo à pesquisa, projetos de pesquisa científica e/ou de inovação tecnológica aos docentes do quadro permanente, em regime de Dedicação Exclusiva do IFPI.

2 Professor do IFPI. 


\section{INTRODUÇÃO}

A utilização inadequada dos recursos naturais, aliada a pouca preocupação das esferas do poder público e a expansão capitalista, demanda pesquisas que busquem estudar o estado da cobertura das terras do Parque Nacional (PARNA) de Sete Cidades, localizado entre as cidades de Piracuruca e Brasileira, Nordeste do Piauí. O Índice de Vegetação por Diferença Normalizada (NDVI) foi utilizado para avaliar o estado da vegetação, ao passo que também foi realizada a caracterização geoambiental da área em estudo.

O NDVI é a aplicação de processos de realce mediante operações matemáticas entre bandas de sensores de satélites, para o estudo foram utilizadas imagens do satélite Landsat 5 TM e Landsat 8 OLI. A referida técnica é de suma importância para medir a densidade de fitomassa foliar fotossinteticamente ativa por unidade de área e avaliar os resultados das atividades humanas em determinadas áreas, cuja fragilidade natural possa desencadear processo de degradação ambiental.

Diante do exposto, os objetivos do presente estudo foram: i) identificar as características geoambientais, ii) caracterizar as atividades desenvolvidas e iii) avaliar o estado de conservação/degradação ambiental da cobertura das terras do PARNA de Sete Cidades (PI), a partir da aplicação do NDVI.

\section{PROCEDIMENTOS METODOLÓGICOS}

\section{Metodologia}

A presente pesquisa utilizou-se de metodologia quantitativo-qualitativa para quantificar, analisar e interpretar os dados. Nesse viés, a cobertura vegetal foi analisada com base no NDVI, mais especificamente, pode-se afirmar que a clorofila na faixa do vermelho absorve a radiação solar, resultando em baixa reflectância. Por outro lado, na faixa do infravermelho próximo a morfologia interna das folhas e a estrutura da vegetação geram alta reflectância da radiação solar incidente (LOURENÇO e LANDIM, 2004). Desse modo, pode-se afirmar que o maior contraste é diretamente proporcional ao maior vigor da vegetação na área imageadas. Logo, a avaliação da conservação/degradação ambiental do Parque Nacional de Sete Cidades foi realizada por meio da aplicação do NDVI, baseado na Equação 1.

$$
\mathrm{NDVI}=(\mathrm{NIR}-\mathrm{R}) /(\mathrm{NIR}+\mathrm{R})
$$

Em que: 
NDVI é o índice de Vegetação por Diferença Normalizada;

NIR é a refletância no comprimento de onda correspondente ao Infravermelho Próximo (0,76 a $0,90 \mu \mathrm{m}$ para o Landsat 5 e 0,85 a $0,88 \mu \mathrm{m}$ para o Landsat 8$) ;$

$\mathbf{R}$ é a refletância no comprimento de onda correspondente ao Vermelho $(0,63$ a $0,69 \mu \mathrm{m}$ para o Landsat 5 e 0,64 a 0,67 $\mu \mathrm{m}$ para o Landsat 8).

Para elaboração do NDVI foram utilizadas as bandas 3 e 4 do satélite Landsat 5 TM, bem como bandas 4 e 5 do Landsat 8 OLI, permitindo medir a densidade de fitomassa foliar fotossinteticamente ativa por unidade de área. As cenas imageadas possuem ponto/órbita 219/63 e data de passagem do dia 17 de setembro para os anos de 1984 e 2013. As referidas imagens foram adquiridas junto ao United States Geological Service (USGS - Serviço Geológico dos Estados Unidos), os dados geoambientais foram extraídos do Plano de Manejo do Parque Nacional (PARNA) de Sete Cidades (BRASIL, 1979).

Os mapas de NDVI, para os anos de 1984 e 2013, e de localização foram elaborados no Sistema de Informação Geografia (SIG) ArcGIS 10.1, produzido pela empresa Environmental Systems Research Institute (ERSI), com licença adquirida pelo Laboratório de Geomática da Universidade Federal do Piauí (UFPI). Para Aquino e Valladares (2013), o referido SIG possui interface gráfica de fácil uso, permitindo carregar dados espaciais e tabulares e visualizá-los sobe forma de mapas, tabelas e gráficos.

Melo et al. (2011) propõe que todos os valores negativos foram convertidos para o nível 1, que representa as melhores condições do NDVI, enquanto que os valores positivos foram condensados até o nível 5, que corresponde ao pior nível de proteção da cobertura vegetal. A referida conversão foi executada através da ferramenta Reclassify do ArcGIS, cujas classes de NDVI para os anos de 1984 e 2013 estão dispostas na Tabela 1. Deve-se destacar que o ano de 1984 apresentou quatro classes e o de 2013 três classes, pois a área em estudo apresenta cobertura vegetal de transição caatinga/cerrado, baixo porte, logo baixa reflectância.

Tabela 1 - Classes de NDVI definidas para o Parque Nacional de Sete Cidades (PI).

\begin{tabular}{c|c|c}
\hline Reclassificação & Faixa de NDVI & Intervalo \\
\hline 1 & Moderadamente Alta & $0,6 \mathrm{a}<0,8$ \\
\hline 2 & Moderada & $0,4 \mathrm{a}<0,6$ \\
\hline 3 & Moderadamente Baixa & $0,2 \mathrm{a}<0,4$ \\
\hline 4 & Baixa & $>0 \mathrm{a}<0,2$ \\
\hline
\end{tabular}

Fonte: Santos e Aquino (2015).

Localização e caracterização geoambientais da área em estudo 
O PARNA de Sete Cidades situa-se no Nordeste do estado do Piauí, entres os municípios de Brasileira e Piracuruca, mais precisamente às Coordenadas Geográficas: 04º5'S e 0415'S e $41^{\circ} 30^{\prime} \mathrm{W}$ e $41^{\circ} 45^{\prime} \mathrm{W}$ (Figura 1). O referido PARNA possui área com 6.221 hectares, delimitado em um perímetro que compreende 36,2 km (BRASIL, 1979).

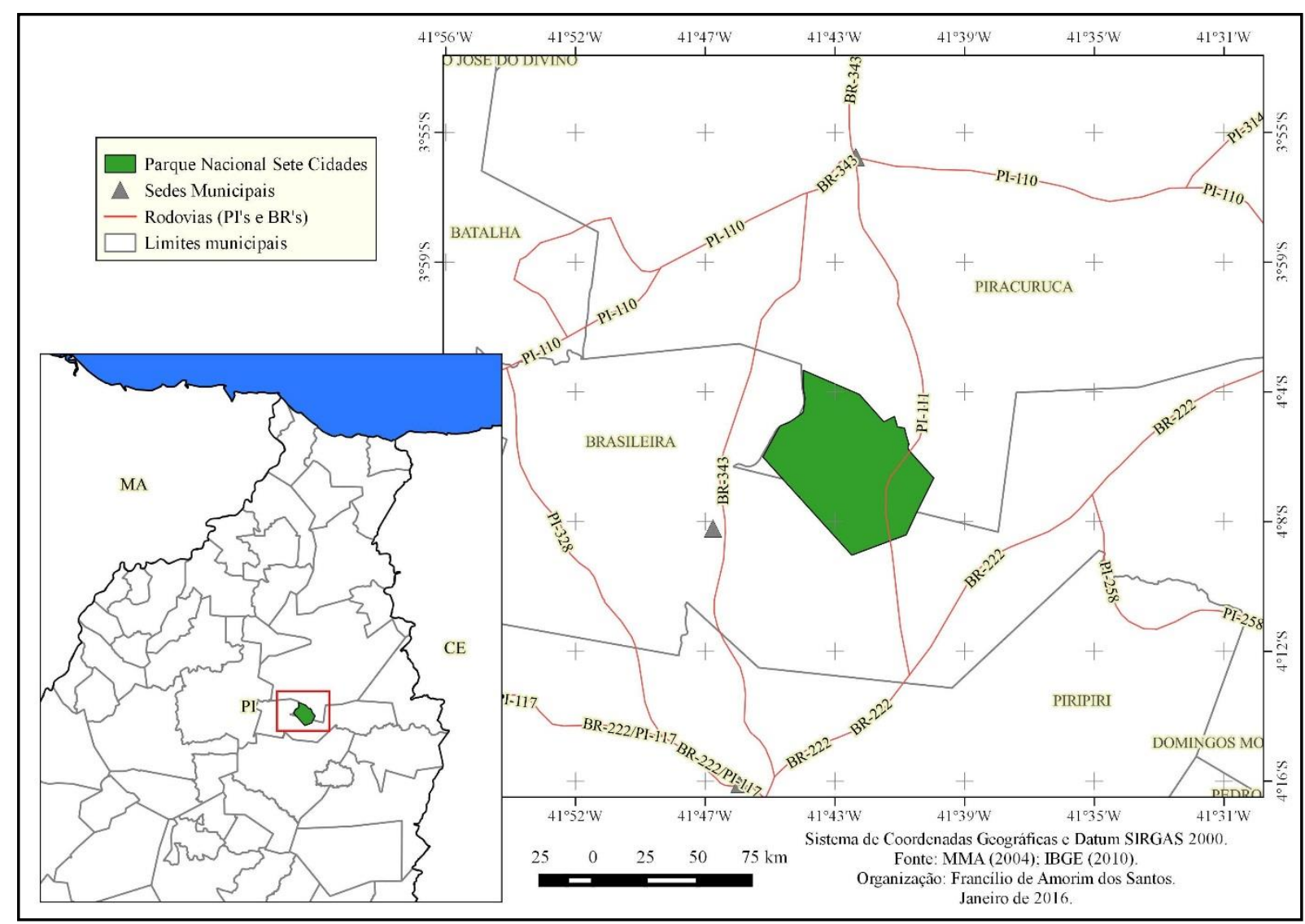

Figura 1 - Localização do Parque Nacional de Sete Cidades, obtido a partir dos dados geográficos do MMA (2004) e da malha municipal digital do Brasil, em escala 1:250.000 do IBGE (2010).

O PARNA de Sete Cidades está situado sobre substrato geológico da Formação Cabeças, que data da Era Paleozóica e Período Devoniano Médio, cuja litologia tem predomínio de arenitos, que apresentam cores claras, brancos, cinza-amarelados chegando a vermelho, médios a grosseiro, conglomerático e muito pouco argilosos, possui aspecto maciço devido sua estratificação espessa, comumente cruzada bem desenvolvida (BRASIL, 1973).

As características geomorfológicas da Unidade de Conservação (UC) abrangem chapadas com relevo remanescente com altitudes variadas que atuam, geralmente, como divisor de águas dos rios Piracuruca e Matos, ambos afluentes do rio Longá. A principal característica topográfica 
é a sequência de superfícies estruturais pediplanas, predominando relevo de linhas suaves. $\mathrm{O}$ PARNA apresenta relevo com altitude representada por uma superfície pediplanas anterior, variando de 60 a $250 \mathrm{~m}$. As maiores altitudes são representadas por testemunhos e as superfícies mais baixas e/ou médias são cônicas e tabulares, representadas pelas serras regionais da Descoberta, Cochicho e Sambaíba. Em alguns locais o modelado encontra-se exposto, denominado monumento geológico que devido erosão apresenta relevo uniforme, cônico e tabular (BRASIL, 1979).

De acordo com o Plano de Manejo do PARNA ${ }^{1}$ sua constituição arenítica alicerça-se da Formação Cabeça apresenta-se bastante porosa e permeável, logo permite escoamento constante. Os olhos d'água de Sete Cidades apresenta-se pouco mineralizada, ácida ou ligeiramente ácida, muito mole, potabilidade boa, geralmente, de coloração clara. Por sua vez, a temperatura estimada para o PARNA apresentou média de $26^{\circ} \mathrm{C}$, com amplitude anual de 2 a $4^{\circ} \mathrm{C}$, enquanto os totais de precipitação pluviométrica médio é $1.554 \mathrm{~mm}$.

A UC em estudo possui três associações de solos, segundo Jacomine (1983): Latossolo Amarelo Álico e Distrófico a moderado, com textura média, recoberto por cerrado subcaducifólio, ocorrendo em relevo plano; Podzólico Vermelho-Amarelo Concrecionário plíntico e não plíntico associado a Solos Litólicos, recobertos por cerrado subcaducifólio e/ou cerrado subcaducifólio/caatinga, presente em relevo suave ondulado e forte ondulado; e Solos Litólicos associado a Podzólico Vermelho-Amarelo Concrecionário, coberto por cerrado subcaducifólio ou cerrado subcaducifólio/caatinga, além de afloramentos de rochas.

As características da cobertura vegetal tipo cerrado com manchas de cerradão, campos abertos inundáveis e matas ciliares apresentam, principalmente, as seguintes espécies: lixeira (Curatella americana), murici (Byrsonima crassifólia), bacuri (Platonia insignis), cascudo (Terminalia fagiflora), faveiro (Parkia platycephala), pau-terra (Qualea grandiflora). Por outro lado, os principais representantes da vegetação tipo caatinga e floresta decídua são: sabia (Mimosa caesalpiniaefolia), jurema (Mimosa sp.), joazeiro (Zisyphus joazeiro), aroeira (Astronium urundenva), macambira (Bromelia laciniosa), xique-xique (Pilocereus gounellę). Quanto às espécies da fauna as principais encontradas são: veado-mateiro (Maz̧ama americana), iguana (Iguana iguana), mocó (Kerodon rupestris) (BRASIL, 1979).

No que tange as atividades desenvolvidas no PARNA estas estão relacionadas à Educação Ambiental (EA), com palestras realizadas aos turistas, cujo conteúdo diz respeito às características históricas e geológicas, com ênfase na conservação ambiental. Além do citado, são

${ }^{1} \operatorname{Idem}(1979)$. 
realizados passeios por trilhas para a visualização dos monumentos geológicos conhecidos como Sete Cidades Encantadas, de acordo com Santos (2012).

\section{Sensoriamento remoto e o Índice de Vegetação por Diferença Normalizada (NDVI): instrumento para análise ambiental}

O século XXI é marcado por uma visão de utilização equilibrada dos recursos naturais. Portanto, de extrema necessidade desenvolver estudo que busca mensurar o nível de conservação/degradação da vegetação. Pois, de acordo com Ross (2010), toda extração de recurso natural realizada pelo homem promove alterações, posto que o simples fato de planejar uma atividade já pode ser considerado um impacto ambiental. Portanto, é imperativo realizar um estudo visando o diagnóstico ambiental, para que se elaborem diretrizes para utilização dos recursos naturais de modo a agredir o mínimo possível a qualidade ambiental.

Atualmente, há uma busca por otimizar as atividades econômicas para fins da sustentabilidade ambiental. Pois acordo com Santos (2008), os níveis de industrialização e urbanização iniciados a partir da Revolução Industrial vêm deixando marcas agressivas ao espaço geográfico, reflexo do modo de produção capitalista. A crescente poluição ambiental e a preocupação com o bem-estar social têm levado pesquisadores a desenvolver testes biológicos mais eficientes, a fim de determinar a sua qualidade sanitária (CONAMA, 2005; CUCHIARA, 2012).

O meio ambiente é o substrato de todas as realizações humanas, sendo desse modo importante objetivo de estudo, especificamente o PARNA de Sete Cidades, que tem 6.221 hectares. O referido PARNA foi criado pelo decreto 50.744/61 (BRASIL, 1961) e é administrado pelo Instituto Chico Mendes de Biodiversidade ( $\underline{\text { ICMBio })}$. De acordo com o Art. $5^{\circ}$, alínea a, do Código Florestal Brasileiro tem como finalidade "[...] resguardar atributos excepcionais da natureza, conciliando a proteção integral da flora, da fauna e das belezas naturais, com a utilização para objetivos educacionais, recreativos e científicos” (BRASIL, 1961, p.3), [...] possibilitando a realização de pesquisas científicas [...] e turismo ecológico (BRASIL, 2000, p.14).

A cobertura vegetal intervém de duas maneiras principais no que concerne à erosão pluvial e, por consequência, no regime hídrico do ecossistema: pela interceptação das precipitações, com seus dois aspectos - hidrológico e energético; pelo fornecimento à superfície de detritos vegetais, que desempenham papel amortecedor (absorção de energia). A cobertura vegetal freia o vento e aumenta a turbulência da passagem do ar. Por outro lado, em espaços sem vegetação o vento pode até remover partículas minerais, originando tempestades de pó e 
formação de dunas. A instabilidade desse meio ambiente impõe severas limitações ao crescimento da vegetação (TRICART, 1977).

Nesse contexto, a utilização de ambientes computacionais de SIG facilita o trabalho para integração de dados de sensores remotos e dados originados de outras fontes, possibilita a análise espacial, a modelagem dos ambientes e a compreensão de determinados fenômenos e projeção de cenários futuros. Portanto, o uso de imagens resultantes do sensoriamento remoto permite ter uma visão de conjunto multitemporal de diversas e extensas áreas da superfície terrestre, permitem visualizar os diferentes ambientes e suas transformações, permitindo observar os principais impactos originados por fenômenos naturais e os antrópicos (FLORENZANO, 2005).

Conforme Florenzano (2008), os sistemas de processamento e análise de imagens, através dos vários softwares disponíveis, possibilitam aplicar técnicas de processamento de imagens, citemse as correções e realce de dados e classificações automatizadas. Por sua vez, as técnicas de processamento de imagens digitais constituem operações numéricas que são aplicadas às imagens. Nessa ótica, o NDVI apresenta importante técnica para estudos na região semiárida de forma a modelar e monitorar o estágio de degradação. Logo, o NDVI consta da aplicação de processos de realce mediante a extração de contraste entre imagens de sensores de satélites, as bandas 3 e 4 do Landsat 5 TM e as bandas 4 e 5 do Landsat 8 OLI.

Accioly et al. (2002), utilizaram transformações espectrais para estimar parâmetros estruturais da Floresta Nacional (FLONA) do Araripe (CE). O estudo indicou que 9\% dos pixels da imagem da FLONA eram outliers, todas as variáveis espectrais têm correlação positiva e significativa com as estimativas dos parâmetros estruturais da altura média da parcela, a altura média da parcela foi a variável estrutural com melhor correlação com as variáveis espectrais, as transformações espectrais apresentaram, em geral, maior relacionamento com as variáveis estruturais, as transformações espectrais que melhor se relacionaram com as variáveis estruturais foi o índice da razão simples e o índice estrutural da vegetação e a fração da vegetação verde proveniente do modelo de análise de misturas não melhorou a predição de dados estruturais.

Silva et al. (2013), utilizaram imagens do satélite Landsat 5 TM, de janeiro e agosto de 2010, buscando identificar e quantificar as queimadas ocorridas no Parque Estadual de Serra Nova através dos índices espectrais NDVI e Índice de Queimada Normalizada (NDBR), confrontando os dados obtidos com a realidade de campo. Desse modo, O NDVI e o NDBR foram eficientes na detecção de áreas queimadas, ao passo que o NDBR é mais eficiente que o NDVI na quantificação de áreas queimadas, portanto, o índice de maior precisão no estudo destas. Dessa forma, devido à área de queimada pertencer ao bioma cerrado, pode-se concluir 
que a resposta da vegetação presente na área alcançou o esperado para o uso do NDVI, mas principalmente no uso do NDBR.

Por sua vez, Castanheira et al. (2014) analisaram qualitativamente a densidade e a intensidade da atividade fotossintética da vegetação com possíveis consequências no fluxo de carbono na região da Floresta Estadual (FEENA) "Edmundo Navarro de Andrade", em Rio Claro (SP). A variação do Índice de Vegetação por Diferença Normalizada (NDVI) das imagens do satélite Landsat, para os anos de 1991 a 2011, cujas médias da série temporal dos mapas apresentaram amplitude total 0,05 e média geral 0,68, apontaram a FEENA manteve nesse período alta densidade e alta intensidade da atividade fotossintética de sua vegetação. Portanto, podendo-se inferir que ocorreu variação positiva do sequestro de carbono da atmosfera na região.

Dentre outros índices para análise da cobertura vegetal, o presente estudo utilizou-se do NDVI como forma de monitorar a cobertura vegetal para fins de conservação dos recursos naturais do PARNA de Sete Cidades. Sendo assim, é pertinente realizar monitoramento da Unidade de Conservação não somente por meio de guardas florestais ou avisos a população que o visita, mas utilizar as geotecnologias disponíveis para subsidiar o planejamento e conservação ambiental. A aplicação do NDVI foi uma metodologia inovadora para o estudo da referida área, ao produzir novos conhecimentos que incorporados aos já existentes, elevando-o a níveis mais complexos.

\section{ANÁLISE E DISCUSSÃO DOS RESULTADOS}

As imagens dos satélites Landsat 5 TM e Landsat 8 OLI permitem afirmar que a cobertura das terras em Sete Cidades apresentam mudanças em seu padrão de proteção, principalmente, no que diz respeito a supressão da classe de maior proteção, Classe-1 Moderadamente Alta, de 1984 para 2013, conforme Figura 2.

De acordo com a Tabela 2, pode-se inferir que houve significativas mudanças nas classes de proteção das terras no PARNA de Sete Cidades, pois de 1984 para 2013 a classe de maior proteção, Moderadamente Alta, foi suprimida. Diga-se, ainda, que a classe Moderada apresentou redução da ordem de 76,7\%, enquanto a classe Moderadamente Baixa apresentou aumento de 24,2\%, de 1984 para 2013. Por sua vez, a classe Baixa aumentou em 62,5\%, de 1984 para 2013. 


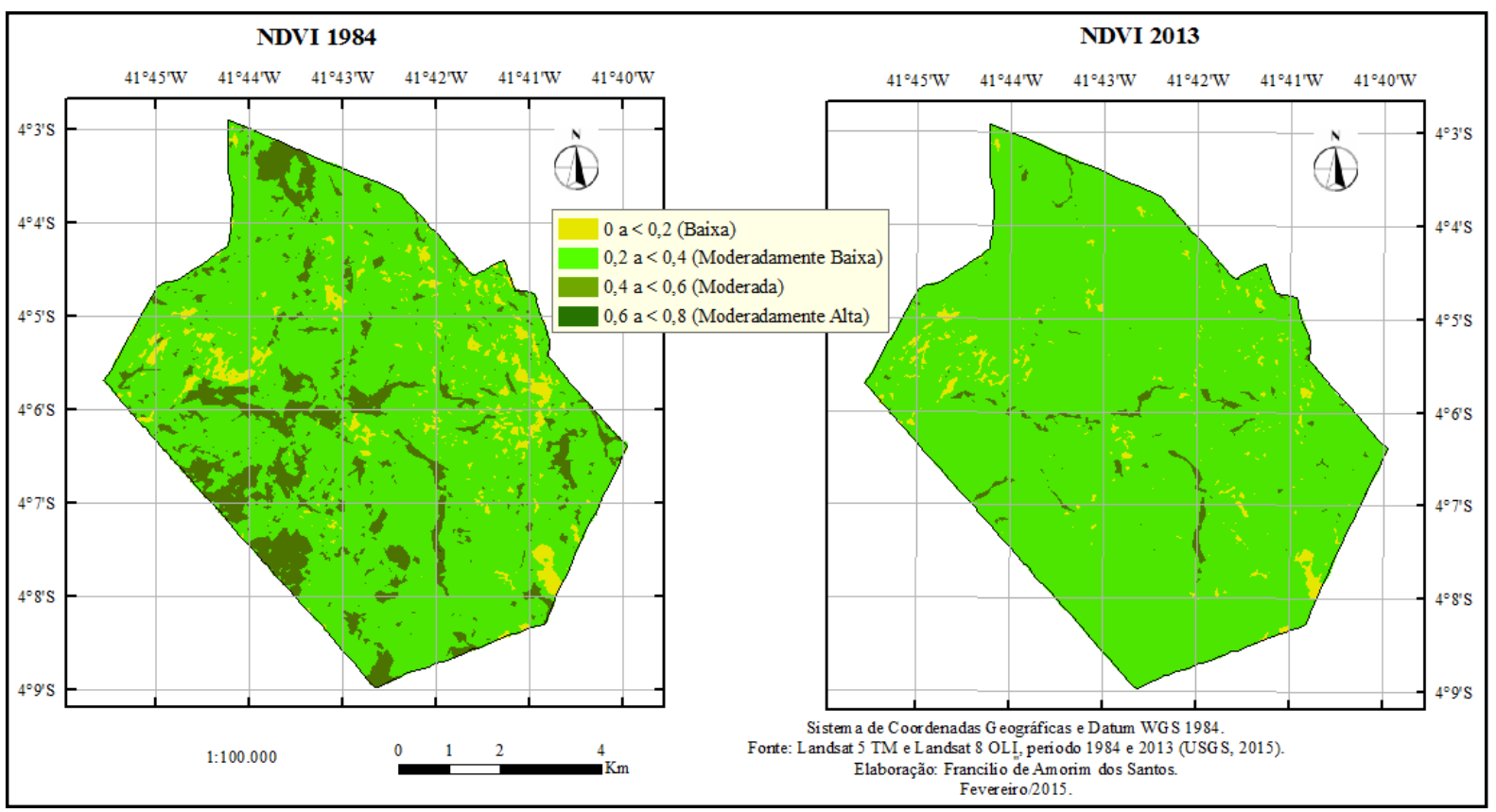

Figura 2 - Índice de Vegetação por Diferença Normalizada (NDVI) do Parque Nacional de Sete Cidades (PI), comparação entre os anos de 1984 e 2013. Fonte: USGS (2015).

Tabela 2 - Distribuição absoluta e relativa dos valores de NDVI, comparação entre os anos de 1984 e 2013.

\begin{tabular}{c|c|c|c|c}
\hline Faixa de Proteção do NDVI & \multicolumn{2}{|c|}{ Área no Nível (hectares) } & \multicolumn{2}{c}{$\%$ da Área Total } \\
\cline { 2 - 5 } & $\mathbf{1 9 8 4}$ & $\mathbf{2 0 1 3}$ & $\mathbf{1 9 8 4}$ & $\mathbf{2 0 1 3}$ \\
\hline Moderadamente Alta & 12,5 & - & 0,2 & - \\
\hline Moderada & $1.094,9$ & 255,1 & 17,6 & 4,1 \\
\hline Moderadamente Baixa & $4.665,7$ & 5798 & 75 & 93,2 \\
\hline Baixa & 447,9 & 167,9 & 7,2 & 2,7 \\
\hline Total & $\mathbf{6 . 2 2 1}$ & $\mathbf{6 . 2 2 1}$ & $\mathbf{1 0 0}$ & $\mathbf{1 0 0}$ \\
\hline
\end{tabular}

Fonte: Pesquisa direta. Santos (Org.), 2015.

Os dados de NDVI apresentaram mudanças no padrão de proteção da cobertura vegetal, pois a classe de maior proteção, Moderadamente Alta, foi suprimida de 1984 para 2013, essas classes são representadas, de acordo com Oliveira et al. (2007), principalmente pelas manchas de floresta tropical e cerrado. De acordo com o autor supracitado ${ }^{1}$, a classe Moderadamente Baixa e Baixa representadas pela caatinga e campos graminóides, respectivamente. A primeira formação

\footnotetext{
${ }^{1} \operatorname{Idem}(2007)$.
} 
apresenta aspecto arbustivo muito aberto e espécies mostrando adaptações à seca, a segunda formação apresenta-se sob a forma herbáceo-subarbustiva bem vigorosa.

\section{CONCLUSÕES}

Os objetivos propostos nesse estudo foram atingidos, posto que foram identificadas as seguintes características geoambientais do PARNA de Sete Cidades: a geologia que diz respeito à Formação Cabeças que data da Era Paleozóica e Período Devoniano Médio; o relevo apresentase sob a forma de chapadas, predominando linhas suaves, destacando-se os morros da Descoberta, Cochicho e Sambaíba; as associações de solos encontrados foram os Latossolos Amarelos, Podzólico Vermelho-Amarelo e Solos Litólicos, tais solos são recobertos por cerrado subcaducifólio, cerrado subcaducifólio/caatinga. Por sua vez, as atividades desenvolvidas no Parque dizem respeito à Educação Ambiental, como palestras, percursos por trilhas para visualização das formações rochosas.

O resultado do NDVI mostrou que houve mudanças nas classes de proteção da cobertura vegetal em Sete Cidades, destacando-se o aumento da área e porcentagem referente à classe Moderadamente Baixa, de 1984 para 2013, representada pelo cerrado. Destaca-se a supressão da classe Moderadamente Alta, de 1984 a 2013, representada pelas florestas tropicais. O resultado do NDVI aponta um estado de sucessão ecológica, principalmente, após os incêndios ocorridos entre 1990 e 2000. Portanto, deve-se buscar desenvolver estudos posteriores que abordem as características físico-químicas dos solos, atualização da capacidade de saturação e do Plano de Manejo para realização de adequado monitoramento das fragilidades naturais.

\section{AGRADECIMENTOS}

Ressalte-se a importância das bolsas de apoio financeiro e incentivo à pesquisa, projetos de pesquisa científica e/ou de inovação tecnológica, destinadas aos docentes do IFPI. Pois o financiamento a pesquisa torna-se de suma importância para o conhecimento de parte do meio ambiente, almejando o planejamento territorial. 


\section{REFERÊNCIAS}

ACCIOLY, L. J. O.; PACHÊCO, A.; COSTA, T. C. C.; LOPES, O. F.; OLIVEIRA, M. A. J. Relações empíricas entre a estrutura da vegetação e dados do sensor TM/LANDSAT. Revista Brasileira de Engenharia Agrícola e Ambiental, v.6, n.3, p.492-498, Campina Grande - PB, UFCG. 2002.

BERTRAND, G. Paisagem e geografia física global: esboço metodológico. RA'EGA, Curitiba, no 8, p. 141-152. Editora UFPR, 2004.

BRASIL. Decreto $\mathbf{n}^{\circ} \mathbf{5 0 . 7 4 4}$, de 8 de junho de 1961. Cria o Parque Nacional de Sete Cidades, integrante da Seção de Parques e Florestas Nacionais do Serviço Florestal, do Ministério da Agricultura.

BRASIL. Ministério da Agricultura. IBDF - Instituto Brasileiro de Desenvolvimento Florestal. Fundação Brasileira para a Conservação da Natureza. Plano de Manejo do Parque Nacional de Sete Cidades. Doc. Téc. No 1. Brasília. 1979.

BRASIL. Ministério de Minas e Energias. Departamento Nacional de Produção Mineral. Projeto RADAM - Levantamento dos Recursos Naturais, Vol. 02, Folha SB. 23 - Teresina; geologia, geomorfologia, solos, vegetação e uso potencial da terra. Rio de Janeiro. 1973.

BRASIL. Ministério do Meio Ambiente. SNUC - Sistema Nacional de Unidades de Conservação da Natureza. Lei No 9.885, de 18 de julho de 2000; Decreto No 4.340, de 22 de agosto de 2002. Introduz alterações pela Lei $\mathrm{N}^{\circ} 11.132$, de 4 de julho de 2006 e pelo Decreto $\mathrm{N}^{\circ}$ 5.556, de 26 de outubro de 2005. $6^{\text {a }}$ edição. Brasília, 2006.

CONAMA - Conselho Nacional do Meio Ambiente. Resolução $\mathbf{n}^{\mathbf{0}}$ 357, de 17 de março de 2005. Dispõe sobre a classificação dos corpos de água e diretrizes ambientais para o seu enquadramento, bem como estabelece as condições e padrões de lançamento de efluentes, e dá outras providências.

CASTANHEIRA, L. B.; LANDIM, P. M. B.; LOURENÇO, R. W. Variabilidade do Índice de Vegetação por Diferença Normalizada (NDVI) em áreas de reflorestamento: Floresta Estadual 'Edmundo Navarro de Andrade'(FEENA)/Rio Claro (SP). São Paulo, UNESP, Geociências, v. 33, n. 3. 2014. p.449-456.

CUCHIARA, C. C.; BORGES, C. S.; BOBROWSKI, V. L. Sensibilidade de sementes de hortaliças na avaliação da qualidade da água em bioensaios. Biotemas, 25 (3), p.19-27, setembro de 2012.

FLORENZANO, T. G. Geotecnologias na geografia aplicada: difusão e acesso. Revista do Departamento de Geografia, vol. 17, p.24-29. 2005.

Sensoriamento Remoto para Geomorfologia. In: FLORENZANO, Teresa Gallotti (Org.). Geomorfologia: conceitos e tecnologias atuais. São Paulo: Oficina de Textos. 2008, p.3671.

GUERRA, A. J. T.; CUNHA, S. B. Geomorfologia: uma atualização de bases e conceitos. Rio de Janeiro: Bertrand, 1995. 
IBGE - Instituto Brasileiro de Geografia e Estatística. Malha municipal digital do Brasil: situação em 2010. Rio de Janeiro: IBGE, 2012. Disponível em: <ftp://geoftp.ibge.gov.br/malhas_digitais/>. Acesso em 27 de agosto de 2015.

JACOMINE, P. K. T. Mapa exploratório-reconhecimento de solos do estado do Piauí. Convênio EMBRAPA/SNLCS-SUDENE-DRN. 1983.

LOURENÇO, R. W.; LANDIM, P. M. B. Estudo da variabilidade do "Índice de Vegetação por Diferença Normalizada / NDVI" utilizando krigagem indicativa. HOLOS Environment, v. 4, n. 1. 2004. p.38-55.

MELO, E. T.; SALES, M. C. L.; OLIVEIRA, J. G. B. Aplicação do índice de Vegetação por Diferença Normalizada (NDVI) para análise da degradação ambiental da microbacia hidrográfica do riacho dos cavalos, Crateús-CE. In: Revista RA'E GA, v.23, Curitiba, Departamento de Geografia - UFPR. p.520-533. 2011.

MMA - Ministério do Meio Ambiente dos Recursos Hídricos e da Amazônia Legal. Download de dados geográficos. 2004.2 Disponível em: http://mapas.mma.gov.br/i3geo/datadownload.htm. Acesso em Acesso em 27 de agosto de 2015.

OLIVEIRA, M. E. A.; MARTINS, F. R.; CASTRO, A. A. J. F.; SANTOS, J. R. Classes de cobertura vegetal do Parque Nacional de Sete Cidades (transição campo-floresta) utilizando imagens TM/Landsat, NE do Brasil. In: Anais XIII Simpósio Brasileiro de Sensoriamento Remoto, Florianópolis, Brasil, INPE. 21-26 abril 2007. p.1775-1783.

ROSS, J. L. S. Geomorfologia: ambiente e planejamento. 8. ed., $3^{a}$ reimpressão. - São Paulo: Contexto, 2010.

SANTOS, F. A. A diversidade e a gestão (in)sustentável dos recursos naturais do Parque Nacional de Sete Cidades, Piracuruca, Piauí. Revista CIENTEC, Vol. 4, no 2, 10-18, 2012.

SANTOS, F. A.; AQUINO, C. M. S. Análise da dinâmica do Índice de Vegetação por Diferença Normalizada (NDVI), dos aspectos econômicos e suas relações com a desertificação/degradação ambiental em Castelo do Piauí, Piauí, Brasil. Revista Electrónica de Investigação e Desenvolvimento, n. 4, p.1-17, junho de 2015.

SANTOS, M. Metamorfose do Espaço Habitado: Fundamentos Teóricos e Metodológicos da Geografia; em colaboração com Denise Elias. - 6. ed. São Paulo: Editora da Universidade de São Paulo, 2008.

SILVA, R. G.; MIRANDA, J. R.; NASCIMENTO, C. R. Detecção de áreas queimadas no Parque Estadual de Serra Nova/MG utilizando os índices espectrais NDVI e NDBR. In: Anais XVI Simpósio Brasileiro de Sensoriamento Remoto - SBSR, Foz do Iguaçu, PR, Brasil, 13 a 18 de abril de 2013, INPE. p.6923-6929.

TRICART, J. Ecodinâmica. Rio de Janeiro, IBGE, Diretoria Técnica, SUPREN, 1977.

USGS - United States Geological Service (Serviço Geológico dos Estados Unidos). Earth Explorer - Collection- Landsat Archive. Disponível em http://earthexplorer.usgs.gov/. Acesso em janeiro de 2015. 